\title{
THE CARDIOGRAPHIC DIAGNOSIS. OF COMBINED VENTRICULAR HYPERTROPHY
}

\author{
BY \\ ANNAMARIA PAGNONI* AND JOHN F. GOODWIN \\ From the Department of Medicine, Postgraduate Medical School of London \\ Received March 11, 1952
}

The introduction of unipolar lead cardiography has renewed interest in the cardiographic diagnosis of biventricular hypertrophy or strain. East and Bain (1948) stated that this diagnosis could often be made with the help of unipolar leads, but recent studies by Garouso et al. (1949), Soulié et al. (1949), Rosenman et al. (1950), and Levine and Phillips (1951) do not entirely support this view. The following investigation was undertaken to determine the frequency of cardiographic findings in this condition and, if possible, to establish reliable criteria for the diagnosis.

\section{CASE Material and Methods}

Three groups were studied: Group I-26 patients with isolated right ventricular hypertrophy; Group II-30 patients with isolated left ventricular hypertrophy; and Group III-51 patients with right and left ventricular hypertrophy. Autopsy confirmation was obtained in all cases and unipolar as well as standard bipolar leads were recorded in all, using a Vector photographic machine and a Sanborn "Visocardiette" direct-writing instrument. Unipolar limb and chest leads were recorded by the technique of Goldberger $(1947)(1 \mathrm{~cm} .=1.5 \mathrm{mv}$. for limb leads. $1 \mathrm{~cm} .=1 \mathrm{mv}$. for chest leads). The standard limb leads have been omitted from the analysis since they did not contribute any information not obtainable from a study of the unipolar leads. All age groups were represented. Cases of ischæmic heart disease, cardiac infarction, or cardiac aneurysm were excluded. Right bundle branch block was present in 3 cases in Group III, and left bundle branch block in 4 cases in Group II and 4 cases in Group III; these cases were excluded from the analysis of cardiographic signs, but were retained in the series as a whole.

\section{Etiology and Pathological Criteria of Ventricular Hypertrophy}

All the common causes of heart disease were found, the most frequent being: in Group I pulmonary heart disease ; in Group II, hypertension; and in Group III, combined aortic and mitral valve lesions, and pulmonary heart disease associated with systemic hypertension.

Three degrees of hypertrophy were recognized. For the right ventricle, a thickness of the wall of 5 to $7 \mathrm{~mm}$. was denoted by,+ 8 to $10 \mathrm{~mm}$. by ++ , and more than $10 \mathrm{~mm}$. by +++ ; for the left ventricle, 15 to $18 \mathrm{~mm}$. was denoted by,+ 19 to $24 \mathrm{~mm}$. by ++ , and more than $24 \mathrm{~mm}$. by +++ . In the few cases in which the wall was not measured in millimetres, an assessment was made in keeping with the above criteria, and based on the weight of the heart. Measurements were made at the outflow tract region of the right ventricle, the maximum muscle thickness being recorded, in both ventricles.

\section{Cardiographic Criteria of Ventricular HyPertrophy}

The features of isolated hypertrophy of the left or right ventricle respectively which were studied have been based on criteria used in this department and on work by Goldberger (1947), Sokolow and Lyon (1949), and Myers (1948 and 1950). The findings indicative of hypertrophy of both ventricles in Group III were derived from these criteria.

* From the Clinica Medica dell'Universita di Milano. 
Right Ventricular Hypertrophy. The following features were studied.

In V1. (1) Ventricular activation time greater than 0.03 of a second measured from the onset of the $\mathrm{QRS}$ to the peak of the $\mathrm{R}$ wave. (2) $\mathrm{R}$ wave greater than $\mathrm{S}$; monophasic $\mathrm{R}$ wave or $\mathrm{qR}$ pattern. (3) Inversion or flattening of the $T$ wave.

In V5. $\mathrm{R}$ wave smaller than $\mathrm{S}$, indicating clockwise rotation of the heart around the longitudinal axis.

In aVR. (1) $R$ wave greater than $Q$, indicating clockwise rotation round the long axis or backward rotation of the apex. (2) $R$ wave greater than $S$. (3) Monophasic $R$ wave.

A pointed $P$ wave more than $2.5 \mathrm{~mm}$. in amplitude in lead V1, suggesting auricular hypertrophy.

Vertical heart as shown by $\mathrm{qR}$ pattern or tall $\mathrm{R}$ wave in aVF with $\mathrm{rS}$ or QS in aVL.

Of these features, only the increase in ventricular activation time and the presence of a larger $\mathrm{R}$ than $\mathrm{S}$ wave in lead $\mathrm{V} 1$ can be considered direct signs. An $\mathrm{R}$ wave smaller than $\mathrm{S}$ in V5, and a predominantly positive deflection in aVR are indirect signs indicative of extreme clockwise rotation of the heart around its vertical axis, or backward apical rotation, which in our opinion is virtually diagnostic of right ventricular hypertrophy in the absence of cardiac infarction, ventricular aneurysm, or right bundle branch block. The presence of an $R$ wave greater than $Q$ in aVR is thought to be a particularly valuable indirect sign especially in children (Goodwin, 1952). An augmented $P$ wave in V1 suggests auricular hypertrophy and is likewise an indirect sign. A vertical position of the heart may occur in normal persons and is not in itself a sign of right ventricular hypertrophy, although frequently associated with it. This criterion has been included for comparison with changes in heart position found in Groups II and III.

Left Ventricular Hypertrophy. The following features were studied.

In V5. (1) Ventricular activation time greater than 0.05 of a second except when the $S$ wave was larger than the R. (2) $R$ wave greater than $20 \mathrm{~mm}$., or, together with $S$ wave in V1, greater than $35 \mathrm{~mm}$. (3) S-T segment depression greater than $\frac{1}{2} \mathrm{~mm}$. and low voltage $T$ wave in relation to high voltage $R$ wave. (4) Flattening or inversion of the initial portion or the whole of the $T$ wave.

In V1. S wave, together with $\mathrm{R}$ wave in V5, greater than $35 \mathrm{~mm}$.

In aVL. When the heart is horizontal and the left arm faces the left ventricle; $\mathrm{R}$ wave greater than $11 \mathrm{~mm}$. if S-T and T wave changes are absent. S-T segment depression of more than $\frac{1}{2} \mathrm{~mm}$. Flattening, low voltage or inversion of all or initial portion of the T wave.

In aVF. When the heart is vertical and the left leg faces the left ventricle; $\mathrm{R}$ wave $20 \mathrm{~mm}$. or more, S-T segment depression and T wave inversion. (Since these changes may occur in gross right ventricular hypertrophy, they cannot be assumed to indicate left ventricular hypertrophy unless associated with evidence of left ventricular hypertrophy in the præcordial leads. Furthermore, as will be seen later, the combination of vertical heart and left ventricular hypertrophy suggests combined hypertrophy.)

$\mathrm{S}-\mathrm{T}$ segment depression and $\mathrm{T}$ wave inversion in leads facing the left ventricle were not accepted as evidence of left ventricular hypertrophy if digitalis had been administered, unless high voltage of $\mathbf{R}$ was also present.

\section{RESULTS}

Fig. 1 shows that there are two striking differences between Groups I and II.

First, in aVL tall $R$ and $S-T$ depression, increase in voltage of the $R$ wave in V5 and $S$ wave in V1 did not occur in Group I.

Secondly, increase in ventricular activation time in V1, with $R$ wave greater than $S$, and $R$ smaller than S in V5, did not occur in Group II.

$P$ wave taller than $2.5 \mathrm{~mm}$., in V1 was seen in 3 cases of right ventricular hypertrophy and 3 cases of hypertrophy of both ventricles, but did not occur in isolated left ventricular hypertrophy. 
Vertical position of the heart was present in two cases in Group II. One of them had an R wave larger than $\mathrm{Q}$ in $\mathrm{aVR}$, associated with pathological evidence of isolated left ventricular hypertrophy. This case merits further attention and will be briefly described.

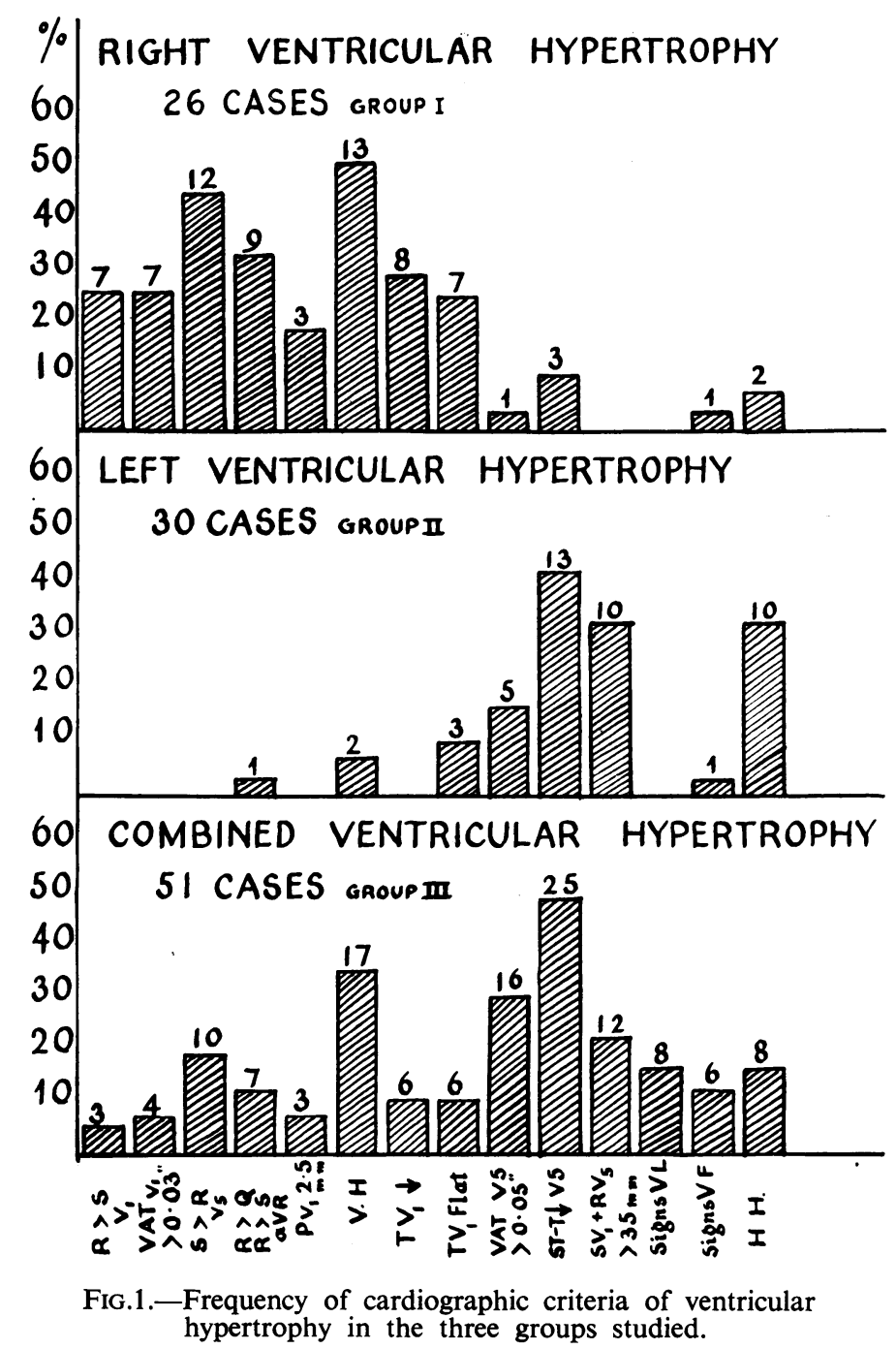

The patient (J.P.) was a girl of 14 years, suffering from subacute nephritis, hypertension and uræmia with pericarditis. The initial electrocardiogram (Fig. 2) showed $T$ waves suggestive of hyperkalæmia but no evidence of ventricular hypertrophy. Shortly before death, she developed left ventricular failure, pulmonary œdema, and pleural effusions. A further cardiogram, 24 hours before death (Fig. 3) showed slight evidence of left ventricular hypertrophy in the form of $R$ greater than $20 \mathrm{~mm}$. in V5. There was inversion of the initial portion of the $T$ wave in V5, which could be ascribed to digitalis. In addition, a large $R$ wave in $\operatorname{aVR}(Q / R$ ratio, 0.6$)$ indicating backward rotation of the apex, strongly suggested dilatation of the right ventricle. Autopsy revealed isolated left ventricular hypertrophy, considerable pulmonary œdema, pleural effusions, and pericarditis. Presumably engorgement in the pulmonary circulation affected the right ventricle, resulting in the cardiographic features described.

In Group I, the ventricular activation time was greater than 0.05 seconds in 4 per cent, and ST-T segment changes were seen in 11 per cent, of cases in V5, but in no case was the sum of the R in V5 
and $S$ in V1 greater than $35 \mathrm{~mm}$. A tall R and S-T depression in aVF was noted in 4 per cent and a horizontal heart position in 8 per cent of cases.

In Group I, 10 cases, which had varying degrees of right ventricular hypertrophy at autopsy, showed cardiographic features indicating extreme clockwise rotation of the heart around the long

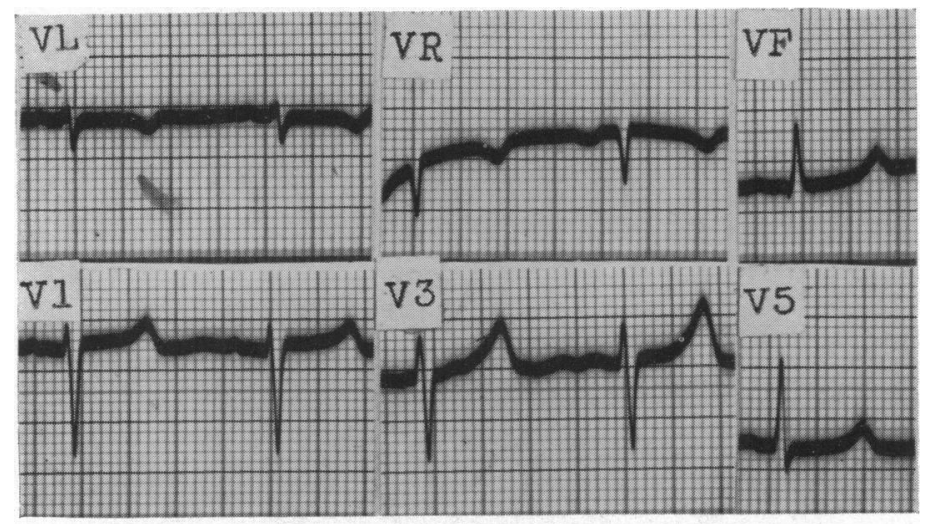

Fig.2.-Case J.P., aged 14. Subacute nephritis and uræmia. Cardiogram showing peaked $T$ waves, but no signs of ventricular hypertrophy.

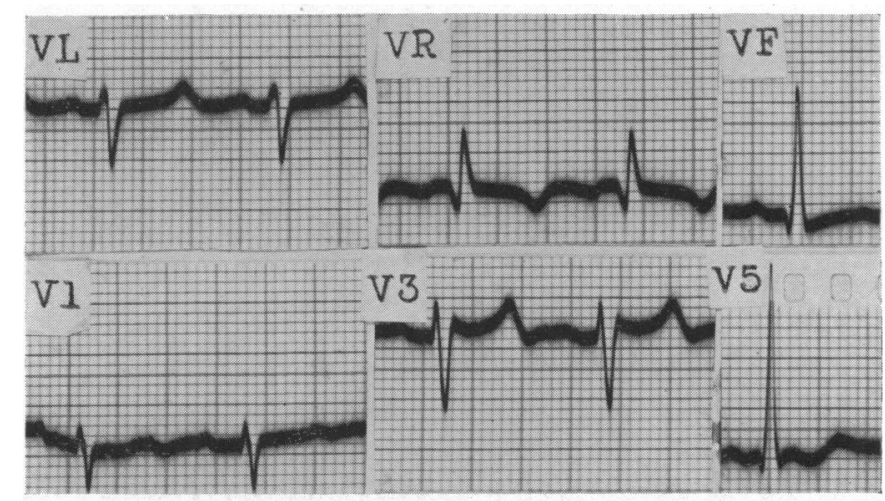

Fig. 3.-Case J.P. 24 hours before death from left ventricular failure and pulmonary œdema. Cardiogram now shows some evidence of left ventricular hypertrophy, RV5 $=20 \mathrm{~mm} .,(+)$ inversion of initial portion of $T$ wave, flat $T$ in VF. In addition, tall $R$ in aVR ( $Q / R$ ratio, 0.6$)$ suggesting right ventricular involvement. Autopsy revealed isolated left ventricular hypertrophy (wall of left ventricle $=16 \mathrm{~mm}$.) but considerable pulmonary œdema and pleural effusions. Terminal right ventricular dilatation produced by left ventricular failure caused rotational changes.

axis, but no direct features of right ventricular hypertrophy. By contrast, in Group II, 3 cases that had an increase in voltage of SV1 and RV5 without S-T segment or T wave abnormalities were found to have moderate degrees of left ventricular hypertrophy at autopsy.

In Group III, signs of left ventricular hypertrophy predominated over those of right ventricular hypertrophy, while the frequency of a vertical position of the heart was slightly less than in Group I but much greater than in Group II. Direct signs of right ventricular hypertrophy were infrequent, 
although indirect signs were more common. An $\mathrm{R}$ wave smaller than $\mathrm{S}$ in V5 occurred in approximately the same number of cases in Groups I and III, but this sign was absent in Group II. R wave larger than Q in aVR was not seen in Group II, with the exception of Case J.P. already described. Inversion of the T wave in V1 was noted most frequently in Group I, but never in Group II.

The cardiographic diagnoses in individual cases in Group III are shown below.

Cardiographic evidence

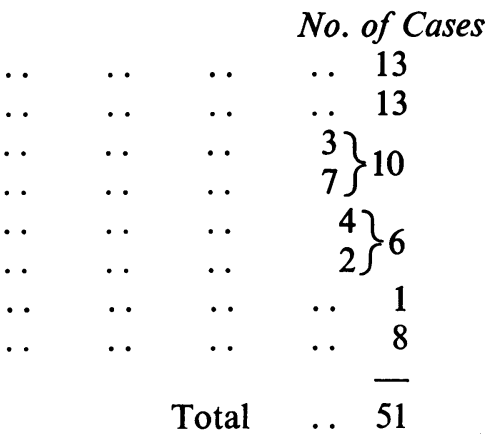

Seventy per cent of cases showed some signs of ventricular hypertrophy, and bundle branch block was present in 6 cases. Of these 70 per cent, signs of isolated left ventricular hypertrophy or combined hypertrophy occurred more frequently than signs of right ventricular hypertrophy.

Fig. 4 is an example of cardiographic signs of pure left ventricular hypertrophy in a patient with gross $(+++)$ left ventricular and moderate $(++)$ right ventricular hypertrophy at autopsy. By contrast, Fig. 5 and 6 illustrate two cases with signs of pure right ventricular hypertrophy, both of which had much right ventricular and slight left ventricular hypertrophy at autopsy. Both these tracings show a prominent $R$ wave in aVR which in Fig. 5 is larger than Q. The S-T segment depression in this cardiogram is due to digitalis.

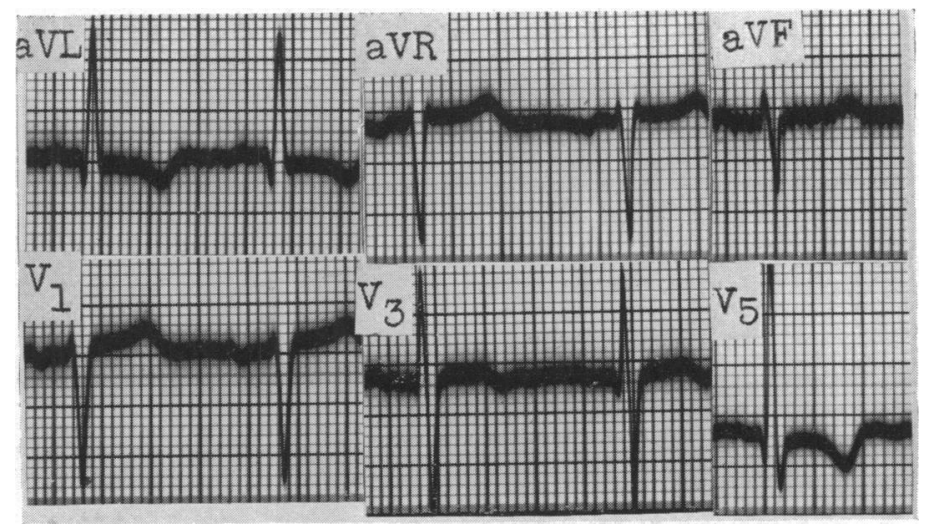

FIG. 4.-Cardiographic evidence of pure left ventricular hypertrophy in a patient with combined hypertrophy due to aortic incompetence and chronic bronchitis and emphysema. (Diameter of left ventricular wall $=25 \mathrm{~mm}$. Diameter of right ventricular wall $=$ $8 \mathrm{~mm}$.) Cardiogram shows horizontal heart, high voltage of $\mathbf{R}$ wave in V5 and aVL, sharp inversion of $T$ wave in V5, aVL.

Table I gives a detailed analysis of 13 cases in which the cardiographic signs were suggestive of combined hypertrophy. Evidence of left ventricular hypertrophy predominated in all these cases and was associated with vertical position of the heart in 7 (Fig. 7, 8, and 12). Case 1 (Fig. 9) showed 
high voltage of $\mathrm{R}$ and $\mathrm{S}-\mathrm{T}$ segment depression with inversion of initial portion of the $\mathrm{T}$ wave in V5, in association with a vertical heart. These features were due to left ventricular hypertrophy

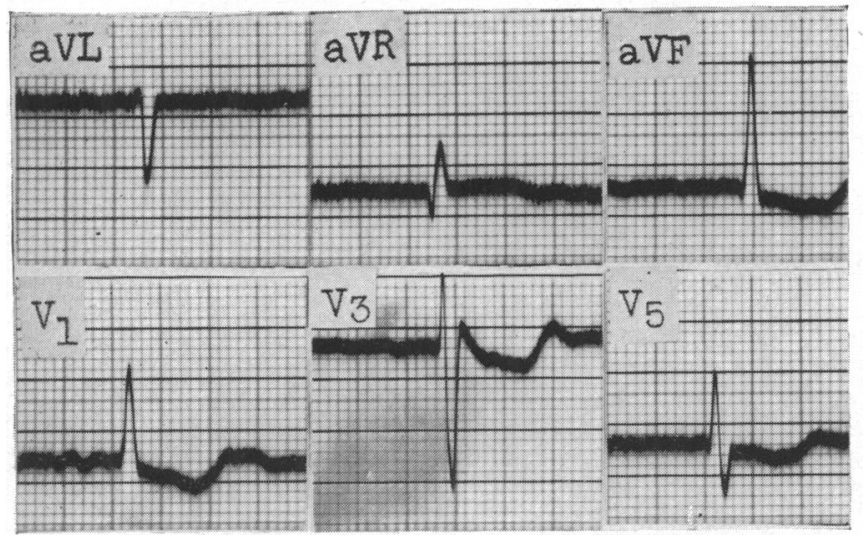

FIG.5.-Signs of pure right ventricular hypertrophy in a patient with combined ventricular hypertrophy due to rheumatic carditis. At autopsy, gross right ventricular hypertrophy and slight left ventricular hypertrophy were present.

The cardiogram shows clockwise rotation round the long axis, monophasic $\mathbf{R}$ in $\mathrm{V} 1$ (ventricular activation time, $0.04 / \mathrm{sec}$.), $\mathrm{qR}$ in aVR (Q/R ratio, 0.4$)$. $\mathrm{S}-\mathrm{T}$ segment depression. The inversion of $T$ waves cannot be ascribed to left ventricular hypertrophy, since digitalis had been given. Auricular fibrillation is present.

FIG. 6.-Signs of pure right ventricular hypertrophy in a patient with combined hypertrophy (hypertension, bronchitis and emphysema). At autopsy, marked right ventricular hypertrophy (diameter of wall, $10 \mathrm{~mm}$.) and slight left ventricular hypertrophy $(17 \mathrm{~mm}$.). Gross clockwise rotation round the long axis, prominent $R$ wave in aVR $(Q / R$ ratio $=1)$, $S$ wave greater than $R$ in V5.

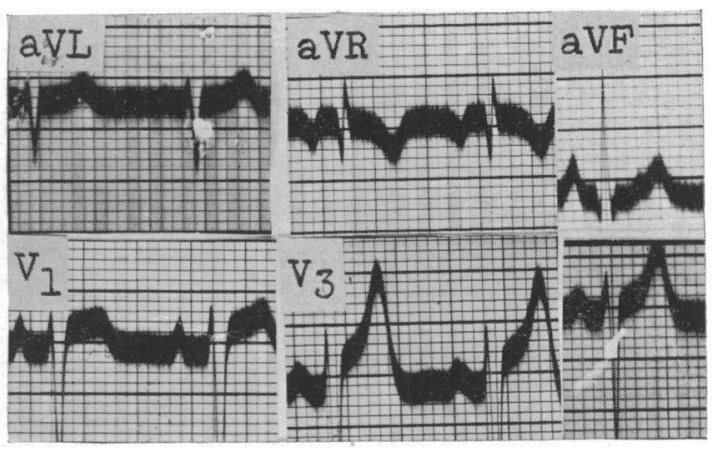

although the S-T segment depression might have been partly the result of digitalis. At autopsy, gross left ventricular hypertrophy and slight right ventricular hypertrophy were found.

An $S$ wave larger than $R$ in V5 indicative of extreme clockwise rotation round the long axis due to right ventricular hypertrophy in Cases 3 and 4 (Fig. 10) was not present in any subject with isolated left ventricular hypertrophy. An S wave larger than R in V5 associated with cardiographic signs of left ventricular hypertrophy and horizontal position of the heart was therefore considered one of the diagnostic patterns of combined hypertrophy.

In Case 2, the large $R$ wave in aVR associated with large $P$ waves and signs of left ventricular hypertrophy is also evidence of hypertrophy of both ventricles (Fig. 11). An $R$ wave greater than $Q$ in aVR was never found with isolated left ventricular hypertrophy, except in J.P., in whom the large $\mathrm{R}$ wave was produced by terminal dilatation of the right ventricle, secondary to left ventricular failure. The $\mathrm{T}$ wave in V1 was flat in Case 8, and inverted in Cases 11, 12, and 13. The inversion of $\mathrm{T}$ in V1, associated with signs of left ventricular hypertrophy, may be accepted as evidence of combined hypertrophy, since it was not seen in any case in which the left ventricle was hypertrophied alone. By contrast, a flat T in V1 was seen in 3 cases of isolated left ventricular hypertrophy, so that its occurrence in Cases 11 and 12, which had no evidence of right ventricular hypertrophy, cannot be assumed to indicate enlargement of the right ventricle.

The relative degree of hypertrophy of either ventricle was not linked to cardiographic signs of hypertrophy of both ventricles. Cardiographic changes due to clockwise rotation round the long 
CARDIOGRAPHIC DIAGNOSIS OF VENTRICULAR HYPERTROPHY

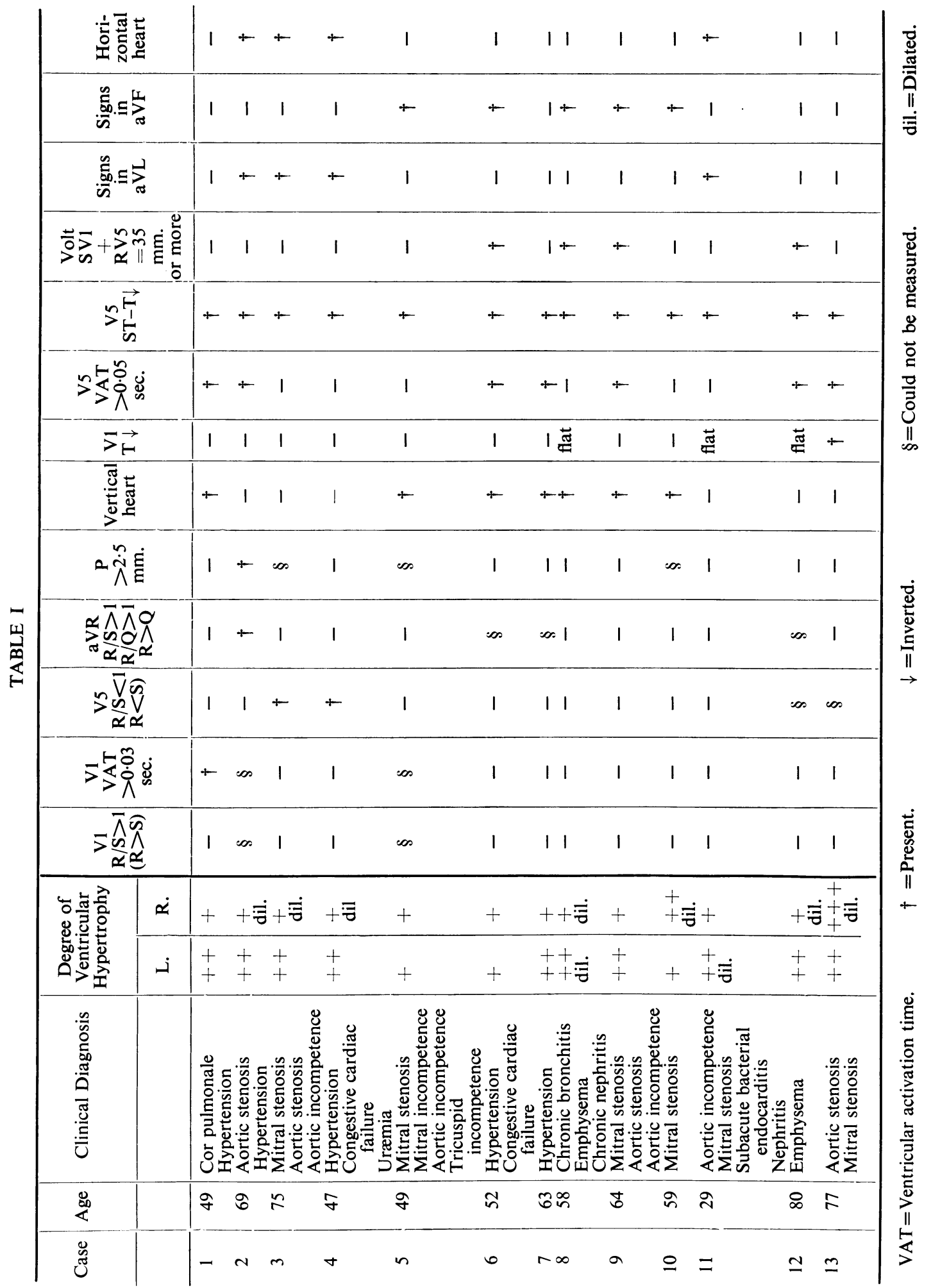


axis of the heart suggesting right ventricular hypertrophy were present in those cases with dilatation of the right ventricle at autopsy. It is therefore likely that dilatation may cause rotation of the heart in these circumstances, as in pulmonary embolism.

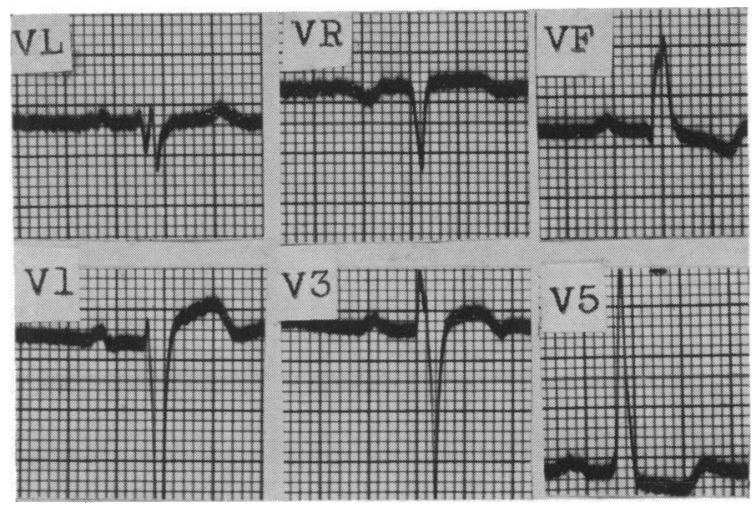

FIG. 7.-Case 6, Table I. Signs of left ventricular hypertrophy with vertical heart in a patient with combined hypertrophy of unknown ætiology. (Autopsy: left ventricle wall, $17 \mathrm{~mm}$. diameter; right ventricle, $7 \mathrm{~mm}$.).

Cardiogram shows RV5 and SV1 greater than $35 \mathrm{~mm}$., S-T depression in V5, inverted TVF. Absence of $\mathrm{q}$ in $\mathrm{V5}$ indicates slight clockwise rotation or incomplete left bundle branch block due to left ventricular hypertrophy. S-T segment depression in V5 may be due to digitalis, but sharp $T$ wave inversion in VF is probably a true sign of left ventricular hypertrophy.

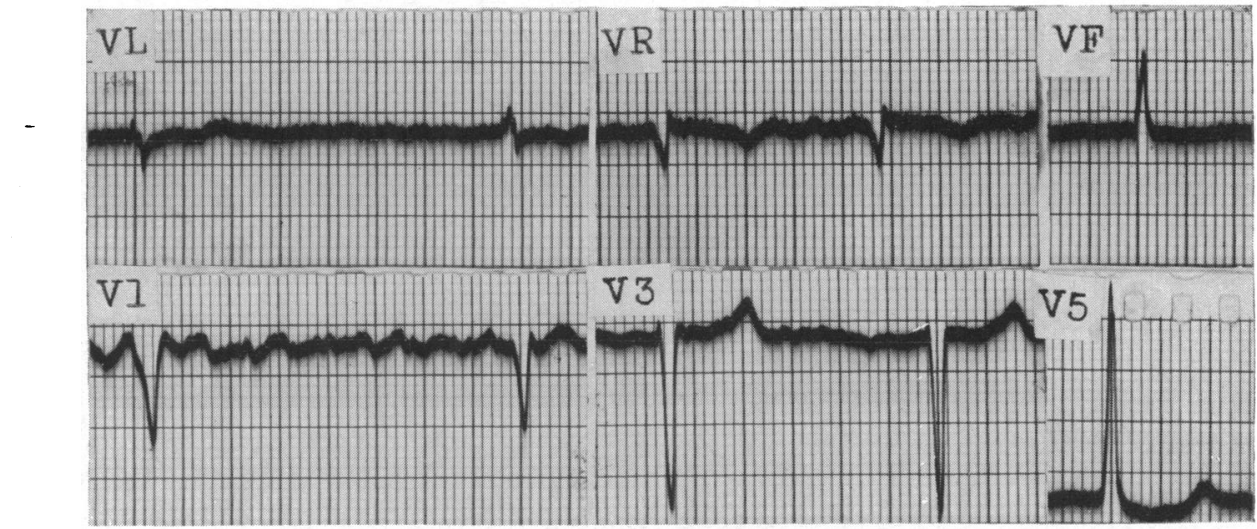

Fig. 8.-Case 5, Table I. Eveidence of left ventricular hypertrophy with vertical heart in a patient with bilateral hypertrophy due to rheumatic carditis. (Autopsy: left ventricular wall $=17 \mathrm{~mm}$.; right ventricular wall $=6 \mathrm{~mm}$. (10 mm. in outflow tract).

Cardiogram shows RV5 $=20 \mathrm{~mm}$., S in V3 $=16 \mathrm{~mm}$., vertical heart. S-T segment depression may be partly due to digitalis. Auricular fibrillation is present.

\section{Discussion}

Only about one-quarter of the cases with hypertrophy of both ventricles is likely to show a characteristic cardiogram. In this series, normal curves occurred in 16 per cent, signs of isolated right ventricular hypertrophy in 20 per cent, signs of isolated left ventricular hypertrophy in 62 


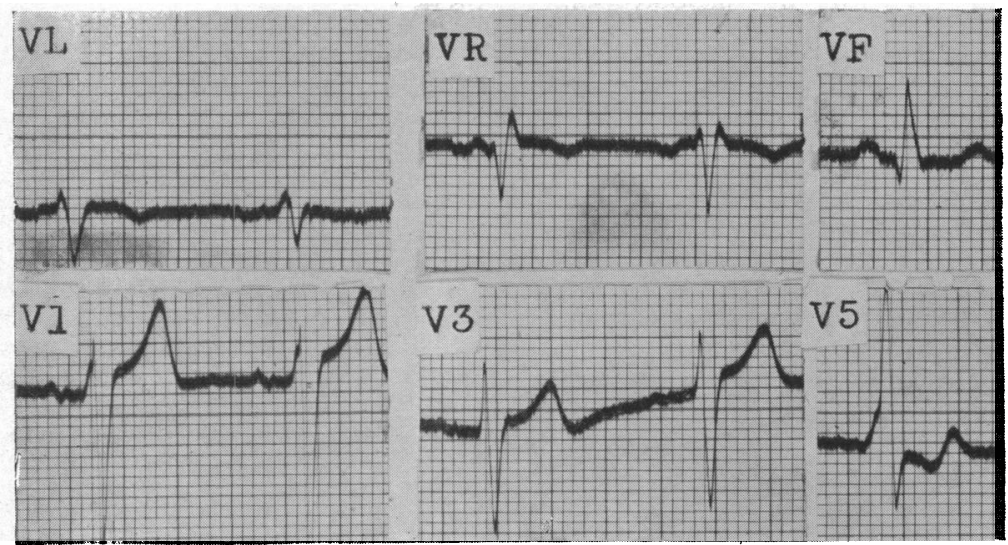

Fig. 9.-Case 1, Table I. Signs of left ventricular hypertrophy in vertical heart in a patient with bilateral hypertrophy due to cor pulmonale and hypertension. (Autopsy: marked left ventricular hypertrophy, slight right ventricular hypertrophy, with dilatation.)

Cardiogram shows vertical heart, RV5+SV1 greater than $35 \mathrm{~mm}$., slurring of upstroke of $R$ in $\mathrm{V} 1$ and V5, QRS duration, $0 \cdot 14 \mathrm{sec}$. in V5. Inversion of initial portion of $T$ in V5. Nodal rhythm.

per cent, bundle branch block in 12 per cent, and appearances suggestive of combined hypertrophy in the remainder.

The results show that evidence of combined hypertrophy may be of two types: (1) definite indications of associated right and left hypertrophy (which did not occur in cases of isolated hypertrophy of one or other ventricle only), and (2) probable indications, which, however, also occurred in a small number of cases of isolated hypertrophy of one or other ventricle respectively.

The definite features consisted of extreme clockwise rotation; $\mathrm{S}$ wave greater than $\mathrm{R}$ in V5 (2 cases), $R$ wave greater than $Q$ in aVR (1 case), $T$ wave inversion in V1 (1 case), in conjunction with signs of left ventricular hypertrophy. Probable features were the association of left ventricular hypertrophy with vertical position of the heart (7 cases). Clockwise rotation of the heart on its long axis, in association with evidence of left ventricular hypertrophy, suggests that the enlarging right ventricle causes this rotation, possibly in displacing the left ventricle posteriorly. The direct signs of right ventricular hypertrophy, namely, increase in activation time of the right ventricle and $R$ wave greater than S in V1, are masked by those of left ventricular hypertrophy. Dilatation of the right ventricle, which may increase the clockwise rotation, was present in 7 of the 13 cases with signs of hypertrophy of both ventricles.

These findings are in general agreement with those of Soulié et al. (1949) and Garouso et al. (1949). These workers all stress the importance of a combination of vertical heart or right axis deviation with evidence of left ventricular hypertrophy. Rosenman et al. (1950), referring only to cases of rheumatic heart disease, found that these criteria did not necessarily apply to cases of left ventricular hypertrophy due to other causes. But, post-mortem confirmation of hypertrophy of one or both ventricles was obtained in only two of their cases. It is of interest that Kaplan and Katz (1941), reviewing the cardiographic patterns of left ventricular hypertrophy, recalled the observation of Thomson and White (1936) that right ventricular hypertrophy is a common sequel to left ventricular hypertrophy.

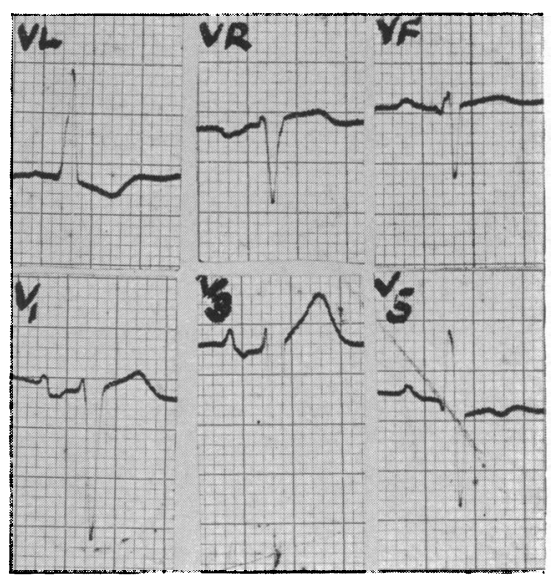

Fig. 10.-Case 4, Table I. Signs of left ventricular hypertrophy associated with extreme clockwise rotation round the long axis in a patient with bilateral hypertrophy due to hypertension. (Autopsy: left ventricle $=$ $21 \mathrm{~mm}$., right ventricle, $7 \mathrm{~mm}$., right ventricle dilated.)

Cardiogram shows horizontal heart, $R$ in $V L=10 \mathrm{~mm}$., $S-T$ depression and $T$ inversion in VL, clockwise rotation with deep $S$ in V5, initial portion of TV5 inverted. 
In the present series 5 of the 13 cases showing combined cardiographic features had lesions of mitral and aortic valves, while 3 cases had lone hypertension or aortic valve disease. Our results suggest that the ætiology of the ventricular hypertrophy does not influence the reliability of the cardiographic criteria. In two cases of isolated left ventricular hypertrophy, a vertical heart

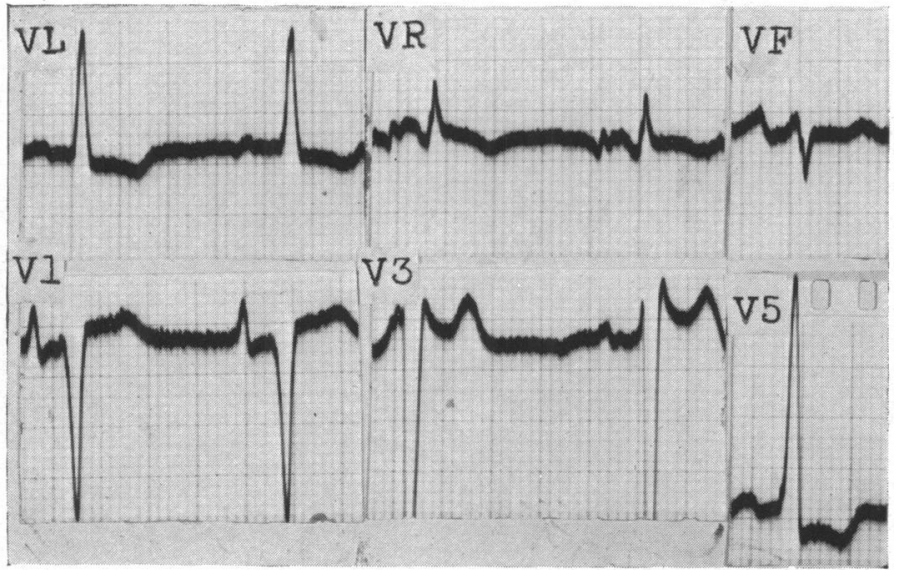

FIG. 11.-Case 2, Table I. Signs of right and left ventricular hypertrophy in a patient with bilateral hypertrophy associated with aortic stenosis and hypertension. (Autopsy: left ventricle, $20 \mathrm{~mm}$., right ventricle, $7 \mathrm{~mm}$., right ventricle dilated.)

Cardiogram shows horizontal heart, RV5+SV1 greater than $35 \mathrm{~mm}$. T wave inversion in V5. Ventricular activation time greater than $0.05 \mathrm{sec}$. in V5. $\mathrm{RaVL}=12 \mathrm{~mm}$. $\mathrm{S}-\mathrm{T}$ depression in V5 and VL. $\mathrm{qR}$ in aVR $(Q / R$ ratio $=0 \cdot 3)$. Augmented $P$ in $V 1$ (3 mm.).

position was associated with signs of left ventricular hypertrophy, and in both the cause of death was renal disease with hypertension. One of these (J.P.) showed cardiographic evidence of terminal right ventricular dilatation as a result of left ventricular failure, and the other had bronchitis during life. Terminal pulmonary engorgement may affect the right ventricle and produce cardiographic appearances that, when superimposed on the findings of hypertrophy of the left ventricle, provide evidence that both ventricles are enlarged.

It is possible that the presence of signs of combined hypertrophy may have some prognostic value in patients with lone aortic or hypertensive disease, as an indication of impending failure of the right ventricle. An $R$ wave larger than $Q$ in aVR, without evidence of right ventricular hypertrophy in V1, has not been mentioned by previous writers, but, as shown in our series, is of some value when present in association with the findings of left ventricular hypertrophy.

Fig.12.-Case 7, Table I. Signs of left ventricular hypertrophy with vertical heart in a patient with bilateral hypertrophy due to hypertensive heart disease. (Autopsy: gross left ventricular hypertrophy, slight right ventricular hypertrophy.)

Cardiogram shows vertical heart, $\mathrm{RV} 5+\mathrm{SV} 1=35 \mathrm{~mm}$. or more, $\mathrm{T}$ wave inversion in V5, S-T segment depression in V5 and VL.

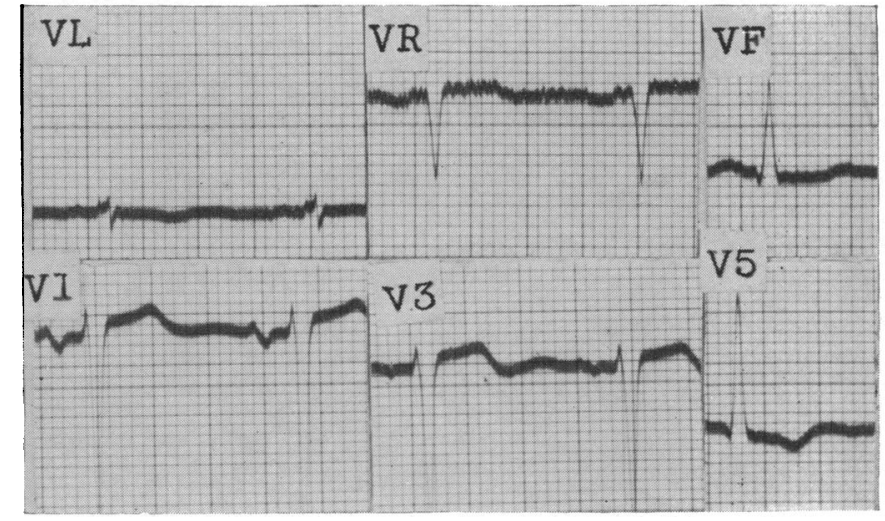

Whereas the presence of the signs of left ventricular hypertrophy in a vertical heart suggests enlargement of both ventricles, the combination of signs of right ventricular hypertrophy with horizontal heart does not provide evidence of combined hypertrophy. 


\section{SUMMARY}

Unipolar lead cardiograms have been studied in 51 patients with combined ventricular hypertrophy, 26 patients with isolated right ventricular hypertrophy, and 30 patients with isolated left ventricular hypertrophy. Autopsy confirmation was obtained in all cases. In the group with combined hypertrophy 13 subjects had signs of left ventricular hypertrophy only and 10 of right ventricular hypertrophy only. Right bundle branch block occurred in two, left bundle branch block in four, non-specific appearances in 8, and evidence of combined hypertrophy in 13 patients.

Direct evidence of right ventricular hypertrophy-increased ventricular activation time and $R$ wave greater than $S$ in V1-was masked by left ventricular hypertrophy. Seven of the 13 cases had features of left ventricular hypertrophy with a vertical heart, and this combination was considered strongly suggestive, but not absolutely diagnostic, of combined hypertrophy, since it was seen in two cases in the control group with isolated left ventricular hypertrophy. One of these cases was thought to have terminal acute right ventricular dilatation secondary to left ventricular failure.

A combination of features of left ventricular hypertrophy, with $S$ wave greater than $R$ in V5 occurred in two cases, and with $R$ wave greater than $Q$ in aVR, and enlarged $P$ in V1, in one case. The association of these rotational signs of right ventricular hypertrophy was not seen in any case of left ventricular hypertrophy without right ventricular enlargement, and their association with signs of left ventricular hypertrophy was considered diagnostic of enlargement of both ventricles. In another case, signs of left ventricular hypertrophy occurred in combination with an inverted $\mathrm{T}$ wave in V1. This did not occur in any case of isolated left ventricular hypertrophy and was thought to indicate associated hypertrophy of the right ventricle.

It is concluded that cardiographic signs of combined hypertrophy are likely to be seen in only about one-quarter of cases in which there is hypertrophy of both sides. The association of a vertical heart with signs of left ventricular hypertrophy is highly suggestive of combined hypertrophy. The presence of an $R$ wave greater than $Q$ in aVR, $S$ wave larger than $R$ in V5 with inversion of $\mathrm{T}$ wave in $\mathrm{V} 1$, together with signs of left ventricular hypertrophy, is diagnostic of combined hypertrophy.

The presence of the cardiographic signs of right ventricular enlargement in addition to those of hypertrophy of the left ventricle due to a pure left-sided lesion may have some prognostic value. Dilatation of the right ventricle may be a cause of specific signs of rotation.

We wish to thank Dr. C. V. Harrison for permission to examine the post-mortem records, and for advice on pathological criteria.

Thanks are also due to Professor J. McMichael, Dr. Terence East, and Dr. David Lewes for advice and criticism.

\section{REFERENCES}

East, T., and Bain, C. W. C. (1948). Recent Advances in Cardiology. Churchill, London.

Garouso, G., Deschamps, H., Tilmant, J., Lenegre, J., and Kalaidonis, P. (1949). Arch. Mal. Caur. $42,711$. Goldberger, E. (1947). Unipolar Lead Electrocardiography. Henry Kimpton, London.

Goodwin, J. F., (1952). Brit. Heart J., 14, 173.

Kaplan, L. G., and Katz, L. N. (1941). Amer. J. med. Sci., 201, 676.

Levine, H. D., and Phillips, E. (1951). New England J. Med., 245, 837.

Myers, G. B. (1950). Amer. Heart J., 39, 637.

--, Klein, H. H., and Stofer, B. E. (1948). Amer Heart J., 35, 1.

Rosenman, R. H., Krause, S., Hwang, W., and Katz, L. N. (1950). Amer. Heart J., 40, 453.

Sokolow, M., and Lyon, T. P. (1) (1949). Amer. Heart J., 37, 161.

(2) (1949). Amer. Heart J., 38, 273.

Soulié, P., Laham, J., Papanicolis, I., and Voci, G. (1949). Arch. Mal. Caur., 42, 791.

Thomson, W. P., and White, P. D. (1936). Amer. Heart J., 12, 641. 